\title{
THE IMPORTANCE OF INPUT AND INTERACTION IN SECOND LANGUAGE ACQUISITION
}

\author{
Ista Maharsi \\ Islamic University of Indonesia
}

\begin{abstract}
The role of input and interaction in second language acquisition has become an unavoidably essential issue to discuss. Abundant research has examined what, how, when, and why input can keep up language acquisition. Many theories are proposed and to some extent implemented and proved to be effective. However, controversies around the role of input are also inevitable. This paper will propose the importance of input and interaction in second language acquisition as were put forward and necessitated by many researchers, how particular input might result in various intakes and how interaction could facilitate output.
\end{abstract}

Key words: input, interaction, second language acquisition

\section{INTRODUCTION}

Input, as well as interaction, is important to L1 as well as L2 acquisition. Research on input in L2 has significantly followed research on input in L1. Whereas the relationship between input and interaction has also received sufficient attention from researchers and how they are together facilitate output.

Both input and interaction play similar importance in second language acquisition process. It could be assumed that different treatment either to input or interaction might affect the process of second language acquisition. More frequent input without being followed by sufficient interaction may not help much the second language acquisition. On the other hand, input which is modified interactionally may result in better development of second language acquisition. 


\section{HOW INPUT INFLUENCES SECOND LANGUAGE ACQUISITION}

Input in L2 acquisition serves as 'an obligatory entry point' that consequently plays a very important role. Without it, L2 learners would not succeed in acquiring the language. Thus, various inputs of L2 acquisition will presumably result in different output. Ellis (2003) proposes two aspects of input that influence L2 acquisition: input frequency and comprehensible input. Input, which is accurate and intensive, will seem to result in better L2 acquisition. In comparison, less number and varieties might cause unsatisfactory L2 acquisition (p. 269). In other words, the more input to L2 learners, the more they will appear in the output (Ellis, 2003; Mitchell and Myles, 2004). Yet, in reality, many factors appear to influence L2 acquisition and to some extent become more complicated because input, output and interaction have cyclical cause and effect or 'chain reaction' one another. There is no certainty when one is done properly, the other will also be well obtained. Indeed, the process is not as simply as it seems.

An important theory of input in L2 acquisition proposed by Krashen (2004) is known as Input Hypothesis. The developed form of this input is that "exposure to comprehensible input is both necessary and sufficient for L2 learning to take place". (p. 165). According to him, learners should be given a lesson which is "a little beyond their current level of competence". Learners are also required to process the input through comprehension and one way to comprehend is through simplification (p. 273). It is important to note that input needs to be processed to become intake. The problem is that not all input can become intake. According to Corder (in Gass and Selinker, 2001), intake is the input which is "internalized" (p. 260). Similarly, Vanpatten and Cadierno (1993) propose that learners should convert input into intake and then again, change intake into acquired systems. In other words, input should be provided sufficiently in order L2 learning can progress. In particular, input should become intake in order to proceed to L2 acquisition. Besides, input should be comprehensible in that learners will not be able to improve when they find that the input is far beyond their mind. Conversely, when the input is too easy, has been well-comprehended and become the part of the acquired system in the learners, the input will be likely to be considered as 'rubbish' which will not make learners progress but could cause frustration. Besides, input should be given systematically in conformity with learners' stage of knowledge. More importantly, input cannot exist alone, because it will not provide anything to language acquisition. Thus, interaction and output should follow the process. 
The process of input to become intake is called the input processing in which strategies and mechanisms are involved to create "form-meaning connections" that will lead to acquisition. Input is considered as "the language that encodes meanings." Besides, input should contain "meaning to which the learner attends for its propositional content" (Vanpatten and Cadierno, 1993, p.46). This may indicate that learners may be able to involve in the input-to-intake stage when they understand what they are learning, and then they restructure the input they get by making association of meanings which will lead them to the content of the learned materials.

In comparison, a research finding shows that the learners' attention to form which is known as "visual input enhancement" (i.e. highlighting, bolding, capitalizing, underlining) seems to show different effects when implemented alone or modified with other forms such as semantic elaboration, a focused production task, or activation of prior knowledge. When alone, visual input enhancement merely results in "sensory detection" because of the highlighting but does not facilitate integrative processing (Izumi, 2002, p.543). These complex aspects of input in a particular step of language acquisition may give alternatives to various strategies to enhance effective input that promotes second language acquisition. From this research, it can be assumed that the strategies of 'paying attention to form' need to be accompanied with other productive and active activities. Accordingly, the process of converting input to intake will be eased by stimulus of input that becomes the stepping stage towards intake.

Other studies about various input are conducted by Pica, Young, Doughty, Loschky, Ellis, Tanaka and Yamazaki about baseline input (the input when Native Speakers listen to other Native Speakers), premodified input (simplified input), interactionally modified input (modified input as a result of meaning negotiation) (Ellis and He, 1999, p. 287). It is known that from various input, interactionally modified input seems to work best, but not as effectively as when implemented to young learners.

Harrington and Dennis (2002) investigate the input-driven in second language learning by referring to previous research findings proposed by many scholars. They propose two regularities that can be extracted from the input that is called as "the simple statistical distribution of forms" such as collocations. The other regularity is indirect regularity that concern with "higher order of structural relations" from the input data such as "the long-distance dependencies governing 
pronominal reference" (p.265). They point out that task frequency plays an important role in second language learning and that input-driven approach "provides an explicit and readily testable account of language learning" (p.262). This may indicate that particular language structure may impose visible effects on language learning when it is provided explicitly and clearly through task frequency.

As has been discussed, the role of input is considered as an important aspect in second language acquisition. However, it is important to note that many kinds of input still need to be processed, activated through interaction and then reflected in the output. Simplified input which is modified with active and productive interaction may encode the underlying meanings of language content. From this, the input may become the active input which is comprehensible and applicable to move towards the interaction. Hence, greater developmental gains could be achieved.

It is also necessary to suggest that teachers and lesson planners need to notice these conditions in order to initiate what is appropriate for learners. Students, in this case, will be facilitated with a learning set that ease them to acquire a language in an effective way. Hence, teachers act as facilitators in learning and acquiring language. In no chance at all teachers are allowed to dominate the learning process. As for doing it, learners will be likely to learn less, passive and under pressure and thus acquisition is a matter of fantasy.

\section{INPUT HYPOTHESIS AND THE BEHAVIOURISM}

The well known input theory is the one proposed by Krashen. In his theory, comprehensible input is seen as a precondition for second language learning to take place. The hypotheses that Krashen proposes (1985) are that learners develop their language through understanding comprehensible input which contains $i+1$ or one level beyond their current competence, input can be turned into comprehensible input if it is simplified, speaking is not the cause of acquisition but it is the result of acquisition. According to his theory, an acquisition can be obtained when learners receive input which is comprehensible. In the next stage, learners will need to change the input into intake.

Many scholars criticize Krashen's input hypothesis because of the vagueness of measuring the competence level of learners. He does not provide the 
way how to know the position of the learners' level in order to know the right time to give them one step higher level of input (Mitchell and Myles, 2004, p. 48). Therefore, many theories that are proposed later seem to improve and give more alternatives on how second language can be acquired. Besides, controversies among the input processing and the output are still debatable.

One of the controversies that is against Krashen's input hypothesis is the behaviorist theory stating that the acquisition process can be controlled by providing learners with "input in the right-sized doses" and also providing the reinforcement of the practices (Ellis, 2003, p. 26). This contrasting view on the role of input in second language acquisition has been widely discussed, yet there has not been an agreement on how far input plays an important role in second language acquisition.

Basically, the behaviorist theory accounts for the existence of stimuli and responses without paying too much attention to the cognitive process in the learners' mind. They also emphasize on the feedback availability as the measurement of input manipulation, which is considered appropriate (Ellis, 2003, p 243).

As the controversies go on, it can be assumed that behaviorism seems to emphasize on the reinforcement or providing stimulus to obtain response. This view sees the consistency of giving what is assumed to be sufficient or at the right dose input then providing the follow up in terms of interaction. Therefore, discussing on input only seems to be insufficient. To get better description and correlation, the discussion on interaction may also be posed as another important aspect in second language acquisition.

\section{INTERACTION: THE INPUT FOLLOW-UP OR THE INPUT POP UP}

Interaction can not be separated from input and output in that interaction acts as the mediator or tools between the two terms. Given that interaction may occur at the same time of input, the interaction process appears to be the practical tools for learners to contextualize the input they get. Furthermore, the terms of input, interaction and output may occur at a few distance of time that the process could be cyclical. A learner, for example, may get input because he/she interacts with either native speakers or non native speakers who speak a second language. Then, at no time at all he/she has to response the stimuli by using the immediate knowledge or 
input. The output, in this case, is the result of instant interaction which can be assumed as the 'activation of previous knowledge'. What is called by 'activation of previous knowledge' is that he/she might have known a little about the second language, and then it is activated. The previous input that he/she had might not be realized but it can emerge as a result of a sudden interaction.

In a more well-planned second language acquisition, just as that of the second language learning, the model of input can be presented and selected in order to meet the needs of the target learners. As the above example is an immediate input-interaction-output process, the well-prepared input-interaction-output may result in better second language acquisition. In comparison, the well-prepared process of giving input, facilitating interaction and thus producing output needs to be mapped and prior objective needs to be determined. This may be called the input follow up (my own term) that shows the possible further steps in second language acquisition. Whereas, the previous example can be called as the input pop up; this refers to the cyclical and immediate process of input, interaction and output.

Interaction or conversation seems to be an instrument to negotiate meaning. To negotiate means to respond properly to the questions which are given (Gass and Selinker, 2001, p. 272). A research finding shows that interaction that involves meaning appears to help learners in L2 acquisition (Loschky in Mitchell and Myles, 2004, p. 168). For example, nonnative speakers often produce inappropriate utterances. Native speakers, in this case, frequently modify the utterances in order to become understandable and it may make the interaction keeps on going. Such interaction is, indeed, helpful for L2 learners to get closer to the model language of the native speakers. Through interaction, L2 learners understand their competence in applying the knowledge they have learned.

\section{INTERACTION HYPOTHESIS AND INTERACTIONIST}

According to the interactionist theories, acquisition could be perceived as "a product of the complex interaction of the linguistic environment and the learner's internal mechanisms, with neither viewed as primary" (Ellis, 2003, p. 243). While there are many interactionist theories, there are two views that are widely discussed: the cognitive interactionists and the social interactionist. The cognitive theory pays more attention to the cognitive processes in the learner's internal mechanisms, whereas the latter sees the importance of "verbal interaction" that is 
perceived to help learners proceed with the association of meanings. These two theories seem to point out the urgency of interaction in order to accomplish second language acquisition.

On the other hand, a well known hypothesis that relates to interaction is Interaction Hypothesis, which is proposed by Long. This hypothesis can be seen as the follow up of Krashen's input hypothesis. The interaction hypothesis concerns with the talk between native speakers-native speakers and native speakers-non native speakers. Accordingly, there could be many issues that emerge from the interaction. Native speakers-native speakers may be involved in a continuous talk without obstacles, while native speakers-non native speakers might create a problem of repetition, clarification, and confirmation (Mitchell and Myles, 2004). Thus, second language acquisition does require interaction as a means to proceed from the input the learners get in order to obtain maximum acquisition or commonly called as 'native-like'.

The intensive interaction between native speakers-non native speakers may result in better second language acquisition in that learners are sufficiently exposed to the target language. Moreover, the language learners who involve in conversational interaction could be said to build the building blocks of language development (Long in Gass and Selinker, 2001). Therefore, it may be indicated that learners can proceed to the interaction stage when they are certain that they have got the language meanings or associate meanings from the interlocutor. This is how an interaction may happen.

Intensive interaction, however, will seem to result in more automatic language learning that facilitates language acquisition. Learners who are exposed to particular language will build cognitive systems that can be activated any time when a stimulus is provided. This issue relates to the fundamental notion in second language acquisition: automaticity and restructuring (Gas and Selinker, 2001). While automaticity has something to do with the linguistic knowledge, the restructuring refers to the "internalized representations as a result of new learning". The more intensive interaction that involves cognitive and social domains, the better the language performance and the closer to second language acquisition are. 


\section{CONCLUSION}

The importance of input and interaction has been perceived to be necessary in second language acquisition. Theoretically, the 'right size and form' of input and the appropriate frequency of interaction will be likely to result in more effective second language acquisition.

However, this paper does not discuss output which is also considered as important as input and interaction. In practice, the three elements input, interaction and outputsupport one another and may occur at the same time of learning. When alone, the elements provide nothing for learners to acquire language but passive information that will remain static. As has been discussed, many research findings still show various influences of input and interaction and the extent to which they promote L2 acquisition. Difficulties in providing sufficient representative data, limitation on particular potential influences on input and interaction have become the major obstacles in similar research. However, those two elements are, indeed, existent and have been proved prominent in L2 acquisition.

\section{REFERENCES}

Brown, H. D. 2001. Teaching by Principles: An Interactive Approach to Language Pedagogy, $2^{\text {nd }}$ Edition, New York: Addison Wesley Longman, Inc.

Ellis, R. 2003, The Study of Second Language Acquisition, Oxford: Oxford University Press.

Ellis, R and He, X. 1999. The Roles of Modified Input and Output in the Incidental Acquistition of Word Meanings. Study of Second Language Acquisition, Vol. 21, p. 285-301.

Ellis, R. 1985 Understanding Second Language Acquisition, Oxford: Oxford University Press.

Gass, S. M. and Selinker, L. 2001. Second Language Acquisition: An Introductory Course, $2^{\text {nd }}$ Edition, New Jersey: Lawrence Erlbaum Associates, Inc.

Harrington, M and Dennis, S. 2002. Input-Driven Language Learning. Study of Second Language Acquisition, Vol. 24, p. 261-268.

Krashen, S. 1985. The Input Hypothesis: Issues and Implications. London: Longman. 
Mackey, A. 1999. Input, Interaction, and Second Language Development: An Empirical Study of Question Formation in ESL. Study of Second Language Acquistition, Vol.21, p.557-587.

Mitchell, R. and Florence, M. 2004. Second Language Learning Theories, $2^{\text {nd }}$ Edition, New York: Oxford University Press.

Izumi, S. 2002. Output, Input Enhancement and the Noticing Hypothesis. Study of Second Language Acquisition, Vol. 24, p.541-577.

Vanpatten, B. and Cadierno, T. 1993. Input Processing and Second Language Acquisition: A Role for Instruction. The Modern Language Journal, Vol. 77. No.1, p. 45-57. 